\title{
Brainy Diabetes Diagnosis and Doctor Recommendation System
}

\author{
M.Rithvik, T. Nagaraju, A. Kalyan Kumar
}

\begin{abstract}
Diabetes is the most common disease that is prevailing now a days from old age people to the young dynamic people which leads to death of the individuals. Eventhough many people are going to hospital in search of a treatment. These treatments may vary from hospital to hospital for the check up and diagnosis. In this scenario there is a need to make people aware of the primitive measures of diabetes and also the treatments as well as the disease intensity stages. This means there should be a treatment from home but not without the presence of a doctor. This paper resembles the diabetes diagnosis system for type1 and type 2 diabetes. With the advent of artificial intelligence things are coming to the door steps. This paper illustrates an upcoming technology that makes the finger print based diabetes test system and generation of reports directly to the doctors. As this is the upcoming technology the base of Artificial Intelligence applications in attaining the application of algorithms like SVM, Linear model and Random Classifier.
\end{abstract}

Keywords: Linear regression, diagnosis, machine learning, Support Vector Machine.

\section{INTRODUCTION}

In this $21^{\text {st }}$ century human life span from 100 is decreased to 55 or 60 years because of rapid food habits and uneven sleep rate that is in turn arising to several dreadful diseases that makes an essence of going towards the death. Diabetes is one of those dreadful cardiovascular disease that leads to the death of the people.

In order to construct a building, there should be a basement and in order to travel a journey of $100 \mathrm{kms}$ an initiative takes place at only 1 mile. In the same way a journey to treat or diagnosis a disease like diabetes an initiative must takes place at one mile in understanding the empathy of patient.

This part is very crucial in any system but with the help of artificial intelligence this part is becoming very minor because in order to understand and observe the condition of patient suffering from time to time needs the seek of a unique system which monitors the condition of patients. This paper introduces few of those elements in patients monitoring system.

Revised Manuscript Received on December 30, 2019.

* Correspondence Author

M.Rithvik*, Assistant Professor, Srk Institute Of Technology, Enikapadu, Vijayawada

T. Nagaraju, Assistant Professor, Srk Institute Of Technology, Enikapadu, Vijayawada

Kalyan Kumar, Assistant Professor , Srk Institute Of Technology, Enikapadu, Vijayawada.

(C) The Authors. Published by Blue Eyes Intelligence Engineering and Sciences Publication (BEIESP). This is an open access article under the CC BY-NC-ND license (http://creativecommons.org/licenses/by-nc-nd/4.0/)
Since technology gives rise to several systems patient health monitoring system is one of those system that uses the sensors and GPS technology to monitor the patient from time to time.

Here in order to develop a system that monitors the risks and precautionary steps in evaluating a diabetes there must be a rubric measurement on the patient attributes as well as the test attributes.

Diabetes disease can be classified into two categories type1 and type2.

Type 1 diabetes occurs at the stage when there is destruction of Beta cells it is very uncommon type and the prediction of this type of diabetes is very difficult

Type2 diabetes occurs at almost all the people it is very common diabetes that is found. It is very dangerous as well.

The cause for any kind of diabetes is the level of insulin that rises than the normal level or decreases from the normal level than expected. The insulin is a protein that is present in the human body.

Prediction of protein secondary structure must be predicted by the various methods and methodologies. It is done by using DSSP and GOR algorithms.

The following figure 1 illustrates a quote on human body by Alfred.

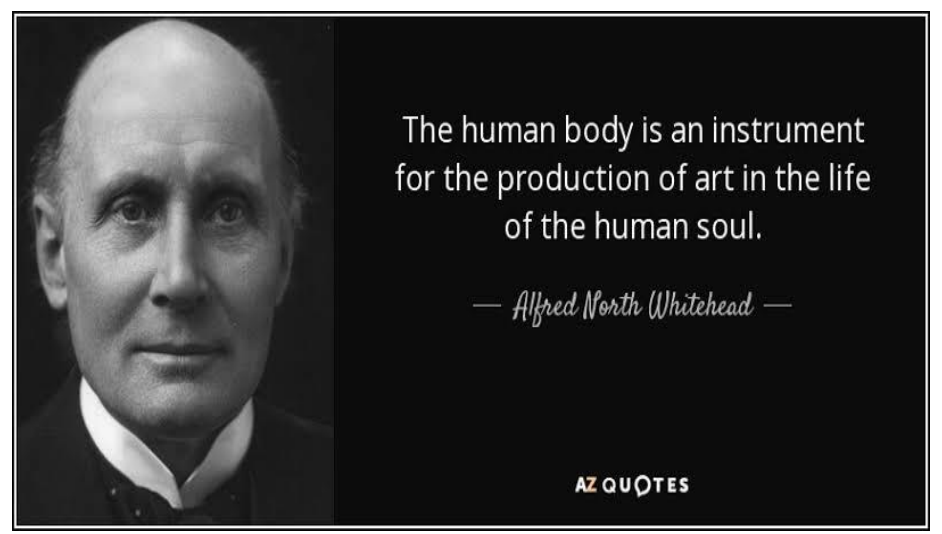

Fig 1: HUMAN BODY QUOTE BY ALFRED

Since human immune system is the only system that measures and prevents from diseases it is essential for a mankind to restrict from various diseases

\section{LITERATURE REVIEW}

Archimedes is the pioneer in the development of a model for diabetes diagnosis. His model based on the symptoms of the patients and initiating a new development model principle that results in diagnosing the diseases like diabetes. 
The patients symptoms are taken into consideration with various attributes like height, weight, BMI and thus insulin level is detected by undergoing various tests like FPG, Random blood sugar [1].

According to the IDF report it is suggested that Diabetes kills one person for every 6 seconds of time. This report plays a very crucial role in the lives of every human beings and in order to detect it and take several precautionary steps to diagnosis the diabetes it is essential to undergo various tests. There is a program called diabetes prevention program, where a person undergoes various tests and the result of tests provide diagnosis to the people who have undergone tests [2]. Now a days it is the great task to estimate the level of patient condition because patient condition can be changed from time to time and the patients seriousness must be estimated from time to time .In this regard patient may undergone several set of treatments in varying hospitals and different hospitals gives different results which may confuse the patient condition. In this regard integrating several technologies in one platform may give some good benefits to the patients who is undergoing some treatment at the hospital in order to diagnosis.[3].

In order to provide and understand the empathy of patients records especially in the treatment of a disease like diabetes needs the support to understand the general structure of diabetes. Insulin can be suggested as a protein secondary structure and to understand the difference in both the structures. In this regard it is essential to understand the alpha and beta helical structure of the protein. This can be captured by using the DSSP and GOR IV codes.[4].

As technology is changing its wings day by day it is essential to come up with the new evaluating technologies in order to resolve the basic problems that we come across IoT is playing a major role in this aspect. A health monitoring system must be introduced to evaluate and check the patient's condition from time to time and provide sufficient glucose if his level is decreased from time to time. There is a tiny sensor that is built in the device of CG Continuous Glucose monitoring system and to evaluate the insulin structure from time to time.[5].Patients records and the patient condition must be stored in the cloud and monitored which is directly linked to a WIFI Module and the results that are captured from the patient record of CG are directly sent to the doctors and labs which result in the fast treatment.

There is a health recommendation system that recognizes the patients health condition based on the patient's life style but this is the system that can be used without the doctors. It is like teaching a class without the teacher help. Teacher deserves the support to understand the empathy of students and doctors need the support to provide good treatments to the patients understanding the empathy.[6].

The HRS and the CG system that work cordially each other must be aligned at an instance. There is a need to recommend good doctors and affordable treatments to the patients because now a days the money that is earned has put for only in the diagnosis of the various diseases. So there is a need to review the medications of doctors and suggest the best medicine to the patient based on a review meeting that saves time of patients and doctors as well.

\section{METHODOLOGY}

The methodology starts with the combination of various streams that are joined with the IoT Based health monitoring system and the recommendation of doctors based on the review meeting. The diabetes data set can be gathered from the koggle.

\section{Step1 : Data Collection}

IoT Based health monitoring system is essential in order to monitor the patient's health condition from time to time. The tiny sensor has been inserted that is used to calculate the blood glucose level and the heartbeat rate along with the BMI.

Heartbeat sensor is used to calculate the digital output of the heartbeat rate when a finger is placed in the IoT device named as Continuous Glucose check. The following figure 2 illustrates the heartbeat levels that are used to monitor the blood glucose and insulin level.

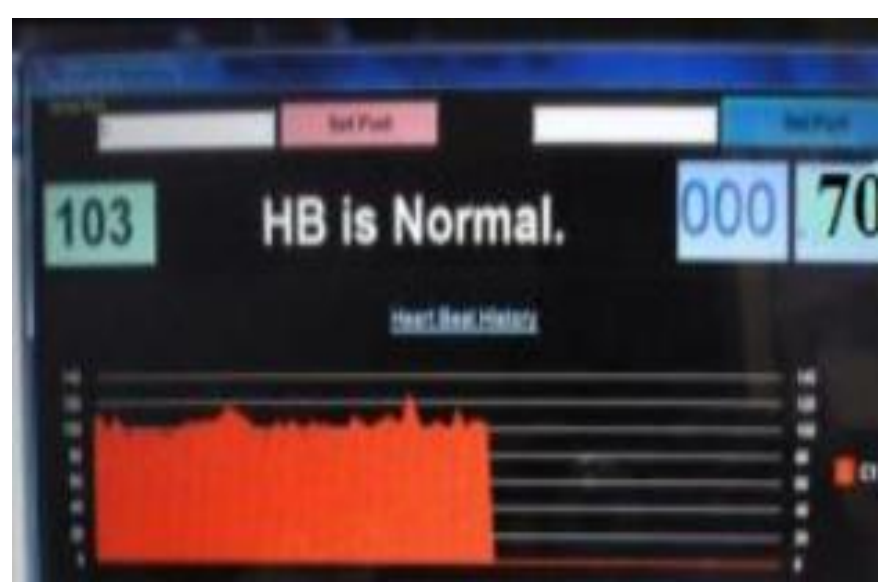

Fig 2: Diabetes health monitoring system

After the Iot Device that produces the desired results it is monitored in the form of a data set that suggests the interaction between the doctors and the reports thus prepared must be sent to the doctors.

A Data set is collected with the collection of health monitoring system data and information gathered from this data set has to be transformed into the machine learning based concept of diabetes prediction system.

The collected data set must undergo various procedures in order to complete the task. The PIMA DATASET that is collected from the internet is transformed with the addition of data that is collected from the IoT Based health monitoring system.

The data report or the data set that is generated from the IoT Based health monitoring system is sent to the nearby labs to monitor the correctness of data. After getting the data in an appropriate manner and readiness is checked from the labs the data set can be sent to next monitoring system. 
Step2: Developing a recommended Machine Learning System

After the data that is collected from the patient history and the patient predefined health analysis there is a need to identify a health care monitoring system that suggests the number of doctors who are nearby and the expert doctors who can give the best treatments.

The FPG,CGTT and the A1C tests that are undergone by the patient are displayed as follows

\section{Rule 1: No Diabetes Range}

If FPG has a level between 70 and $100 \mathrm{mg} / \mathrm{dL}$ then this condition indicates- no diabetes range.

If the blood glucose level below $125 \mathrm{mg} / \mathrm{dL}$ in CGTT, then this condition indicates - no diabetes range.

If HBA1C value is below $97 \mathrm{mg} / \mathrm{dL}$, then this condition indicates- no diabetes range.

Rule 2: Pre-diabetes Range If the FPG ranges from 100 $\mathrm{mg} / \mathrm{dl}$ to $125 \mathrm{mg} / \mathrm{dl}$ and CGTT ranges from $140 \mathrm{mg} / \mathrm{dl}$ to $199 \mathrm{mg} / \mathrm{d}$ and HBA1C test values lie in range 97-154 $\mathrm{mg} / \mathrm{dL}$, then this condition indicates the pre-diabetes range.

Rule 3: Diabetes Range If FPG is $126 \mathrm{mg} / \mathrm{dl}$ or more and CGTT is $200 \mathrm{mg} / \mathrm{dl}$ or more and HBA1C is greater than $180 \mathrm{mg} / \mathrm{dL}$, it indicates diabetes.

After attaining the information of the patient who has undergone these tests the collected data set is sent to the doctors in order to evaluate the conditions of patients and the patients information as well as doctors information must be communicated in vice versa manner.

The results that are produced are communicated via a review meeting conducted by the doctors and the suggested doctor information is sent directly to the patients.

\section{Step 3: SVM Based Doctor Recommendation System}

In order to understand and evaluate the recommended doctors A web based assessment system is developed based on the SVM and the suggested doctors are recommended.

\section{Step 4:Training the data sets}

The data set that is captured is implemented in a hospital that consists of at least 5000 patients to measure and monitor the status of patients.

\section{Step 5: Analysis of Predicted Results}

The results that are captured from the hospitals after a level of training may vary from time to time and it is essential for the coordinator to ordinally communicate the same information to the updation.

\section{RESULTS AND DISCUSSION}

The whole scenario of data set when it is applied in the hospital of 5000 people have undergone the implementation of several algorithms like SVM,LINEAR REGRESSION AND RANDOM FOREST

The data set thus obtained has displayed the desired results of the random forest algorithm that is shown in figure3

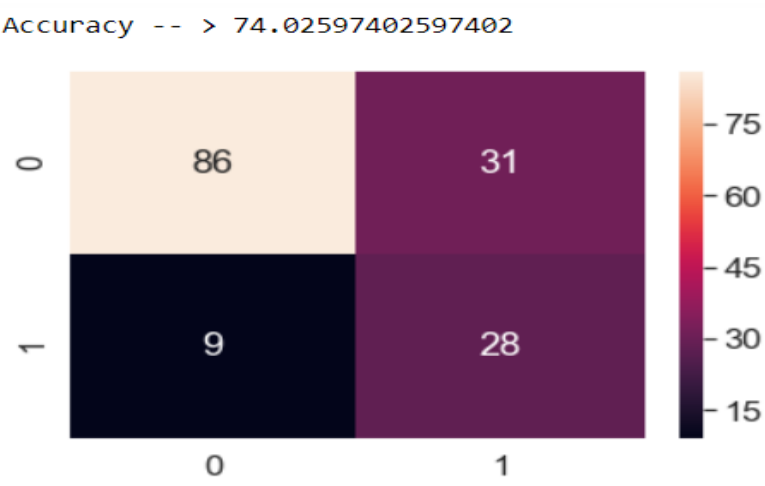

Fig 3: Random Forest algorithm

As this algorithm is mainly used for the purpose of classifying the data that is given for testing and training it may not give that much accurate results but with the help of this algorithm the tests classification and the doctors classification can be done in an easier way.

Later the SVM is used in order to attain the doctors information that suggest the nearby doctors proceeding doctors as well as the expert doctors information for the treatment of diabetes. It is shown in the below fig 4

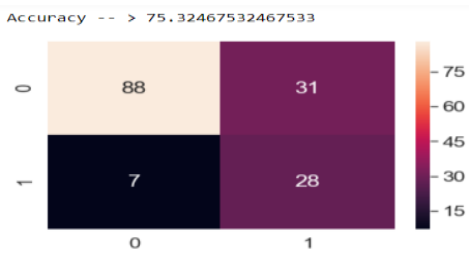

Fig4 : SVM

A linear model acquiring linear regression is implemented in the last stage as shown in fig 5

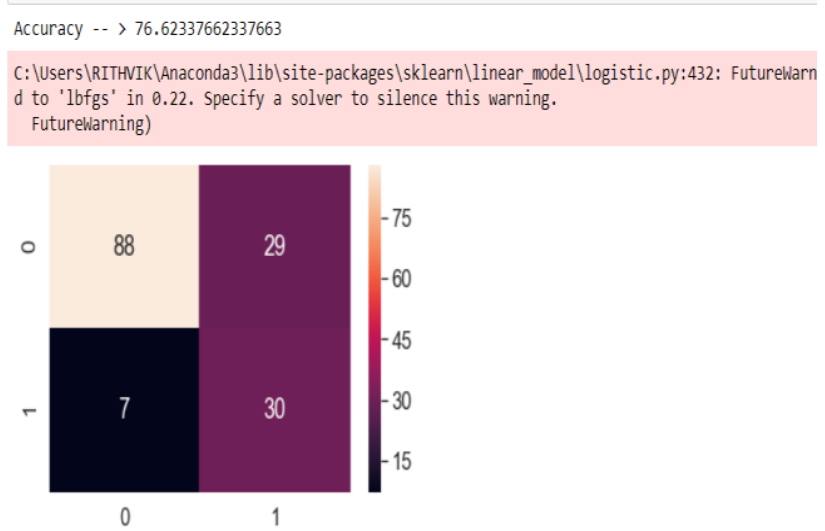

Fig 5 : LINEAR MODEL 
All the results are tabulated as follows

\begin{tabular}{|l|l|l|}
\hline S.NO & METHOD USED & ACCURACY \\
\hline 1 & LINEAR LREGRESSION & $76.62 \%$ \\
\hline 2 & SVM & $75.32 \%$ \\
\hline 3 & RANDOM FOREST & $74.02 \%$ \\
\hline
\end{tabular}

\section{CONCLUSION}

The above discussion deals with the implementation of a new domain in the era of medical field.This sort of approach suggests that the system that is working with the new domains like IoT,AI and ML must work jointly with the mankind as well. A doctor is the only person who can understand the empathy of the patient even though there are trying to replace him it is not possible because he is the pioneer of medications. This technology suggests a framework to reduce the efforts of patients and the doctors thus providing a collaborative service in making both of them work easier and efficient.

\section{REFERENCES}

1. M.Rithvik,G.Nageswara Rao,"An Innovative Approach to Diabetes Diagnosis" (IJCSIT) International Journal of Computer Science and Information Technologies Vol. 6 (3) ， 2015， 1986-1989 ISSN::0975-9646

2. M. Rithvik," Nageswara Rao G. (2015) A Comparative Study of Methodologies of Protein Secondary Structure. In: Muppalaneni N. Gunjan V. (eds) Computational Intelligence Techniques for Comparative Genomics. SpringerBriefs in Applied Sciences and Technology. Springer, Singapore

3. M.Rithvik,Ch.Ambedkhar,A.Kalyan Kumar," An Inception Framework to Diabetes Diagnosis with Techniques of Ai" 2018 JETIR December 2018, Volume 5, Issue 12 ISSN-2349-5162

4. DPP-4 Inhibitors TatjanaÁbel National Health Center Hungary: A New Therapy of Type 2 Diabetes

5. American Diabetes Association Standards of Medical Care in Diabetes 2015

6. Eddy DM1 ,Schlessinger L) Archimedes: a trial-validated model of diabetes.

\section{AUTHORS PROFILE}

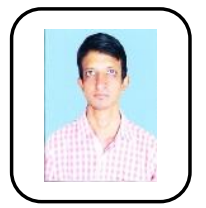

Gold medalist in M.Tech in IT Department. "A STUDENT's Vision is a teacher's mission is his quote" that makes me to succeed a class in my teaching in order to make a student wait for my class.Worked as a teaching assistant under TEQIP in ADITYA INSTITUTE OF TECHNOLOGY AND MANAGEMENT, TEKKALI, Srikakulam FOR 2

years.

Worked as a DATABASE ADMINISTRATOR in VSOFT Technologies for 5 months, Hyderabad.Worked as an APSDDC MENTOR unde ASPIRE FELLOWSHIP for 8 months.Working as Assistant Professor in CSE DEPARTMENT IN SRK INSTITUTE OF TECHNOLOGY, Enikapadu, Vijayawada from JUNE $5^{\text {th }} 2017$ to till date CISCO CCNA CYBEROPS CERTIFIED.

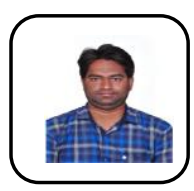

Working as an Assistant professor for the Department of CSE in SRKIT, Worked as an Assistant professor for the Department of CSE in SVISIT ,Tadepalligudem,West Godavari (Dist),Andhra Pradesh From May'2018to Till Date.One Year of experience in the field of Teaching as an Assistant Professor for the reputed organization in Andhra Pradesh.B.Tech(CSE) and M.Tech(CSE) at Graduate and Post Graduate levelsTaught the subjects at the levels of B.Tech.Placement Coordinator for the Dept of CSE.Worked for college Website.Worked as Online Exams Incharge.Attended workshop at reputed institution under FDP

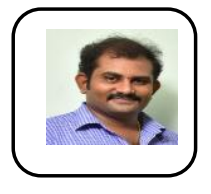

Working as Assistant Professor in CSE Department in SRKIT.Commitment to work and good learning skills.Good Decision making and easily adaptable to environment.Belief in team work and good communication skills.Participated as an NSS volunteer in "NSS CAMP" in the year 2011.Participated in “ANDROID WORKSHOP” in the year 2012. Worked with the mini-project "ACSE ENCLOSURE" in the year 2012. Worked as a team member for the main-project "SECURING NODE CAPTURE ATTACKS FOR HIERARCHIAL DATA AGGRIGATION IN WIRE-LESS SENSOR NETWORKS" in the year 2013. Worked on the project "HUMAN BEHAVIOR ANALYSIS USING SMARTPHONE DATA” in our college in the year 2017.Certified as MICROSOFT TECHNOLOGY ASSOCIATE from DATABASE ADMINISTRATION FUNDAMENTALS and INTRODUCTION TO PROGRAMMING USING JAVA. 